\title{
VINTE E CINCO ANOS DE ESTUDOS DA PALEONTOLOGIA, COM ÊNFASE NA FLORA GONDWÂNICA
}

O.Rösler ${ }^{1}$

\section{INTRODUÇÃO}

O presente resumo procura apresentar uma sinopse dos resultados e, mais propriamente, da natureza e abrangência das pesquisas realizadas por mim isoladamente ou em conjunto com colaboradores, particularmente com meus pós-graduandos. Tendo iniciando a carreira científica com Ecologia Vegetal, posteriormente Hidrobiologia, passei a me dedicar a Paleontologia em 1965 na Universidade Federal do Paraná e, a partir de 1969, na Universidade de São Paulo. Embora procurando abranger diferentes campos dessa disciplina, maior dedicação foi dada às plantas fósseis.

\section{DESCOBERTA DE NOVAS OCORRÊNCIAS FOSSILÍFERAS}

Centenas foram descobertas por nossa equipe. Para se entender o que isso significa em termos relativos, pode-se mencionar que, se levarmos em consideração apenas as plantas fósseis do Paleozóico Superior da Bacia do Paraná, um levantamento no início da década de 70 computou cerca de 30 (trinta) ocorrências então conhecidas. Hoje, computando apenas o trabalho de nossa equipe nessa área, esse número superou 300 (trezentas) novas ocorrências estudadas.

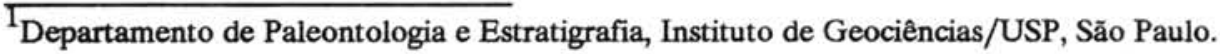




\section{COLEÇÕES PALEONTOLÓGICAS}

Através do trabalho de coleta, preparação, triagem e catalogação feita por nossa equipe, foram incorporadas as coleções científicas do IGc-USP mais de 6.000 (seis mil) amostras de fósseis (RÖSLER, 1982, 1989, p.17).

\section{ESTUDOS DESCRITIVOS}

A descoberta de dezenas de novas espécies e de novo material de numerosas localidades estudadas pela $1^{\mathrm{a}}$ vez abrange principalmente vários grupos de plantas fósseis como licófitas, esfenófitas, felicíneas, coníferas e angiospermas, além de animais fósseis como tentaculitóides, icnofósseis, insetos, peixes e répteis (RÖSLER, 1974; RÖSLER et al., 1981; RÖSLER \& ROHN, 1984 e muitos outros; ver RÖSLER 1989, p.19-23).

\section{ABRANGÊNCIA GEOGRÁFICA}

12 trabalhos tratam da paleontologia da Bacia do Paraná em geral. Outros trabalhos abordam 2 ocorrências do RS, 4 de SC, 21 do PR, 8 de SP, 1 de GO, e 2 do PI. Três trabalhos abordam aspectos da América do Sul em geral, além de um sobre o Chile. Cinco trabalhos referem-se à pesquisas no norte da Península Antártica (CZAJKOWSKY \& RÖSLER, 1985, e outros) e três abordam aspectos mais gerais da região Gondwânica (ROHN \& RÖSLER, 1987; RÖSLER, 1988, 1989a).

\section{ABRANGÊNCIA CRONOESTRATIGRÁFICA}

Quanto a abrangência cronoestratigráfica, referentes ao Siluriano e Devoniano, dedicamos 3 trabalhos; Neopaleozóico em geral, 17 trabalhos; Carbonífero e Permo-Carbonífero, 5; Permiano Inferior, 19; Permiano Superior, 20; Mesozóico e Cenozóico, 5 , além de trabalhos mais gerais, em número de 5 (RÖSLER, 1989 p.31-32). 


\section{ABRANGÊNCIA TEMÁTICA}

Além dos trabalhos taxionômicos descritivos, foram produzidos alguns envolvendo aspectos bioestratigráficos, paleofitogeográficos, e relações de fauna e flora.

\section{TRABALHOS EM ANDAMENTO}

Até início de 1992 deverá estar em fase final uma obra contendo uma síntese atualizada sobre as floras dos continentes gondwânicos (desde América do Sul até N.Zelândia, incluindo a Antártica), do Siluriano Superior até Eoceno, realizada conjuntamente com renomados especialistas de mais de 20 países participantes do "IGCP Project 237: Floras of the Gondwanic Continents" (UNESCO/IUGS).

a) Divulgação científica - Uma constante atividade de divulgação científica, particularmene da Paleontologia, enfatizando seu contexto multidisciplinar, fez parte das metas do autor no presente resumo. Até a presente data, 71 palestras e conferências foram proferidas em escolas de vários níveis, em várias ocasiões, principalmente no Brasil, mas também em 8 outros países. Vinte e oito artigos didáticos e de divulgação foram produzidos, não computando a assessoria inúmeras vezes prestada a órgãos de imprensa.

b) Criação de apoio a grupos de trabalho - Orientação a grupos de trabalho e/ou doação de fósseis coletados durante as pesquisas acima mencionadas igualmente foi uma meta prioritária nesse período, beneficiando instituições, como o antigo Museu Paranaense (Curitiba, PR); Museu Câmara Cascudo (Natal, RN); Instituto de Geociências da Universidade de Brasília; Faculdade de Filosofia e Ciências de Botucatu (UNESP de Botucatu, SP); UNICAMP (Campinas, SP); Instituto de Pré-História da USP; Universidade Federal de Sergipe (Aracaju, SE); Programa Antártico Brasileiro, PROANTAR (CIRM); UNISINOS (São Leopoldo, RS); Universidade Federal do Ceará (Fortaleza, CE); Universidade Federal do Paraná (Curitiba, PR), e Universidade Federal do Acre (Rio Branco, Acre), além de apoio prestado a alguns grupos de trabalho no próprio Instituto de Geociências e em outras unidades da USP.

c) Formação de recursos humanos - A meta de maior prioridade foi a de formar recursos humanos para a pesquisa científica. Dessa forma, grande parte das pesquisas mencionadas foram realizadas paralelamente à orientação de 47 estagiários e das dissertações e teses de: Fernando C Fittipaldi, Miriam N.Diniz, José A.J. Perinotto, Rosemarie Rohn, José H.G. Ciguel, Rafael G. Martins Neto, Livia Maria Casele, Murilo R. de Lima e Peter McAllister 
Rees. A grande maioria dos estagiários publicou trabalhos científicos e vários deles, assim como os pós-graduandos, participaram da autoria de tabalhos mencionados na presente sinopse.

\section{BIBLIOGRAFIA CITADA}

Mais de uma centena de trabalhos (incluindo alguns resumos com trabalhos ainda não publicados) poderiam ser relacionados para ilustrar a abrangência acima sumariada, o que seria incompatível com as normas da presente publicação. São, portanto, relacionadas apenas alguns exemplos mencionados no texto acima.

\section{REFERÊNCIAS BIBLIOGRÁFICAS}

CZAJKOWSKI, S. \& RÖSLER, O. (1986) Plantas fósseis da Península Fildes (Shetlands do Sul): morfolografia das impressões foliares. Anais da Academia Brasileira de Ciências, (Suplemento), 58:99-110.

ROHN, R. \& RÖSLER, O. (1987) Relações entre a flora permiana gondwana e as flores das províncias setentrionais. In: CONGRESSO BRASILEIRO DE PALEONTOLOGIA, 10., Rio de Janeiro, 1987, Resumos da Comunicaçōes, Rio de Janeiro, Sociedade Brasileira de Paleontologia. p.60-61.

RÖSLER, O. (1974) Novas espécimes de Sphenophyta Formação Rio Bonito (Permiano) no Estado do Paraná. Boletim IG, 5:17-28.

RÖSLER, O. (1982) Coleções de megafósseis vegetais do Instituto de Geociências (Departamento de Paleontologia e Estratigrafia), Universidade de São Paulo. Boletim de la Asociacion Latinoamericana de Paleobotanica y Palinologia, (8):1-20.

RÖSLER, O. (1988) Project 237:- Floras of the Gondwanic Continents. Geological Correlation, (16):61-62. 
RÖSLER, O. (1989a) Sistematização crítica da obra. Texto preparado para o concurso de Livre Docência junto ao Instituto de Geociências da USP, 61p. (Disponível na Biblioteca do IGc-USP).

RÖSLER, O. (1989b) Floras of the Gondwanic Continents. Geological Correlation, (17):69-71.

RÖSLER, O.; ROHN, R.; ALBAMONTE, L. (1981) Libélula permiana do Estado de São Paulo, Brasil (Formação Irati): Gondvanoption brasiliense gen. et sp nov. In: CONGRESSO LATINO-AMERICANO DE PALEONTOLOGIA, 2., Porto Alegre, CNPQ/PETROBRÁS/FAPERGS, 1981. Anais. Porto Alegre. V.1, p.221-232. 